УДК 004.9

Ю.В. Ковальова

\title{
МОДЕЛЮВАННЯ ТОПОЛОГІЇ БЕЗДРОТОВИХ СЕНСОРНИХ МЕРЕЖ
}

Анотація. До числа основних проблем досліджень бездротових сенсорних мереж (БСМ) відносяться моделювання та управління топологією мережі з метою підвищення ї зв'язності, а також маршрутизація з мінімальними часовими і енергетичними затратами. В роботі здійснено порівняння можливих топологій БСМ між собою та розглянуто статистику кінцевої затримки, пропускної здатності, завантаження. Результати вказують на те, що деревоподібна мережа має більшу пропускну здатність $і$ кінцеву затримку. Крім того, згасання погіршує продуктивність мережі та накладні витрати на маршрутизацію. Зроблено висновок, що продуктивність мережі з топологією зірки прийнятна для малих мереж, тоді як на основі сітки найкраще підходить для мереж з великою кількістю мобільних вузлів.

Ключові слова: математична модель, топологія, бездротова передача, сенсорна мережа, енергомоніторинг, вузел.

Постановка проблеми. Відстань і час більше не є перешкодами, оскільки люди та речі тепер спілкуються між собою просто натисканням кнопки або управління жестами. Живі та неживі істоти, позначені невеликими електронними пристроями, які називаються сенсорними вузлами, обмінюються бездротовим зв'язком, передаючи сприйняті дані в найближчі або віддалені місця, де дані або інформація необхідні для подальшої обробки. Застосування цієї нової технології охоплює всі аспекти життя, такі як побутові, промислові, логістичні, авіаційні, медичні, виробничі. Цю нову парадигму називають Інтернетом речей (IoT) [1], основний матеріал якого становлять бездротові сенсорні мережі (БСМ). БСМ складається з крихітних сенсорних пристроїв, обмежених ресурсами, що називаються вузлами.

До числа основних проблем досліджень БСМ відносяться моделювання та управління топологією мережі з метою підвищення її зв'язності, а також маршрутизація з мінімальними часовими і енергетичними затратами [2, 3]. Під топологією БСМ зазвичай розуміють модель, що описує структуру зв'язків між елементами всередині мережі. Однак рішення даних проблем неможливо без

(C) Ковальова Ю.В., 2021 


\section{«Системні технології» 1 (132) 2021 «System technologies»}

урахування станів зв'язку між вузлами. Відсутність ефективного підходу до оцінки різної взаємодії вузлів призводить до того, що теоретичні розрахунки за спрощеними моделям топології БСМ не співпадають з результатами експериментальних досліджень мереж.

Аналіз останніх досліджень. Вузлами в БСМ керує супервузол, який, у свою чергу, передає всі зібрані дані в місця, які можуть знаходитися в межах або повністю поза периметром мережі датчиків. Протоколом, який контролює та регулює функціонування БСМ, є стандарт IEEE 802.15.4 [2, 3]. Механізм надає вузлу негарантований спільний доступ до середовища передачі за допомогою суперкадру (див. рис. 1), який генерується координатором персональної мережі (PAN). Щоб досягти тривалого терміну експлуатації, обмежена потужність вузлів датчиків повинна бути обережно використана, оскільки вони в основному живляться автономно від батареї.

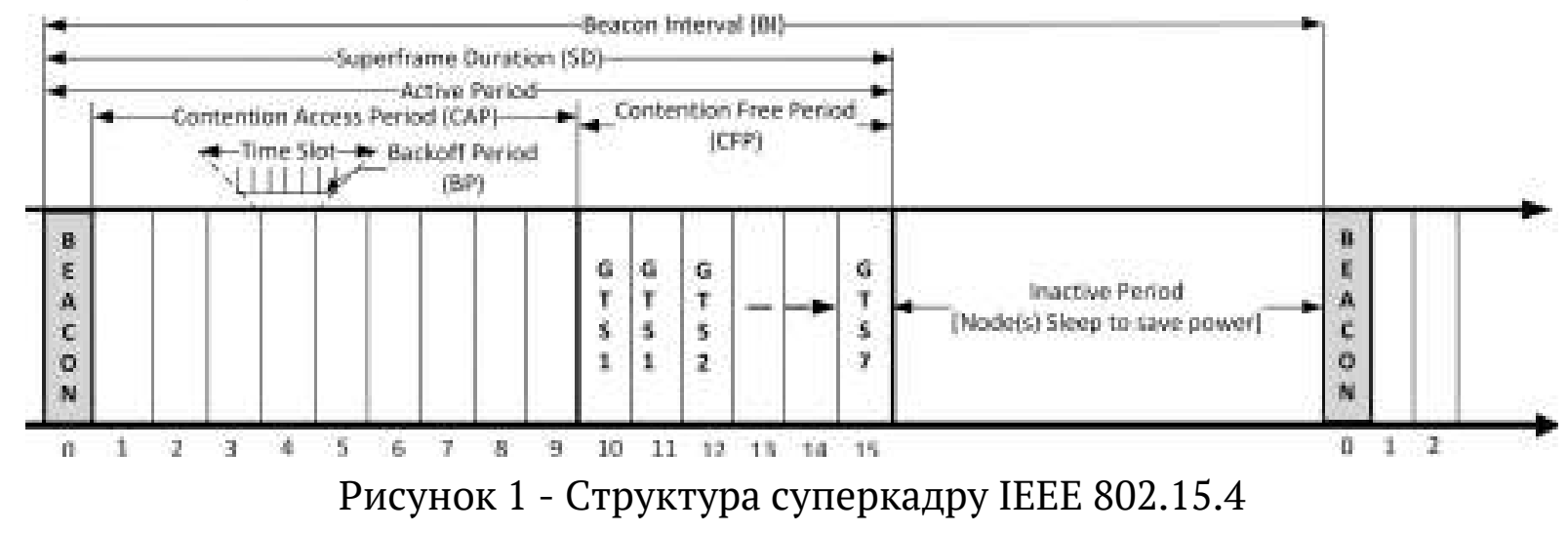

Вимога на обмеження енергоспоживання поширюється на сенсорний вузол і на конструкцію мережі. Наприклад, вибір зроблений на фізичному шарі сенсорного вузла впливає на енергоспоживання всього пристрою і конструкцію рівнів, розташованих вище. Топологія «зірка», при якій точка збору має стаціонарне живлення, а кінцеві вузли з автономним живленням доставляють їй пакети по прямому з'єднанню, є найбільш простою конфігурацією мережі, при цьому час безперебійної роботи кінцевих пристроїв максимальний. Недолік даної топології полягає в малій гнучкості і обмеженій сфері застосування. У найбільш загальному випадку мережа може мати багаточарункову топологію, в якій всі вузли є маршрутизаторами, що дозволяє будувати більш надійні та економічно розвинені системи. Але середнє енергоспоживання вузлів зростає, і його розрахунок ускладнюється. Термін служби елементів живлення вузла буде істотно залежати від його положення в топології мережі i напрямків проходження мережевого трафіку. Топологія «шина-зірка»є при- 


\section{«Системні технології» 1 (132) 2021 «System technologies»}

кладом комбінованої архітектури БСМ і являє собою послідовне з'єднання ряду підмереж зі структурою «зірка». Такий варіант відрізняється високою масштабованістю і простотою супроводу, оскільки дозволяє додавати і видаляти пристрої без істотного впливу на інші елементи мережі. Однак при цьому вихід з ладу одного з ланок шини призведе до відмови у доступі до мережі всіх нижчестоящих вузлів. У мережі 3 архітектурою дерева передача даних і повідомлень управління через мережу здійснюється 3 використанням ієрархічної стратегії вибору маршруту i може проводиться під централізованим управлінням, для чого на фізичному рівні потрібно використовувати періодичні сигнали маяків від координаторів IEEE 802.15.4. Коміркові мережі використовують однорангові зв'язки, маршрутизація в таких мережах є децентралізованим, розподіленим по мережі процесом. Попередній порівняльний аналіз топології бездротових сенсорних мереж показав, що топологічна цілісність і гарантована якість обслуговування вузлів мережі потенційно досяжні тільки у двох топологій - зірка і чарункова архітектура. При цьому топологія зірка дозволяє отримати гарантований час опитування вузлів мережі, а коміркова архітектура - високу живучість бездротової сенсорної мережі [4-7]. Необхідні подальші дослідження впливу топології БСМ на їі зв'язність та маршрутизацію з метою мінімізації часових і енергетичних витрат.

Метою даної роботи $є$ моделювання топології БСМ за критеріями, які враховують вимоги до пропускної спроможності по лініях зв'язку з урахуванням внутрішніх перешкод.

Викладення основного матеріалу. Алгоритм моделювання топології мережі складається з наступних основних етапів:

- Розрахунок відстаней між вузлами.

- Визначення радіуса зони радіозахвату (radio capture zone) передавача як можливого джерела перешкод.

- Розрахунок потужності сигналу з передавача $j$-го вузла, що оцінюється на вході приймача $i$-го вузла.

- у припущенні про наявність канального шуму на рівні чутливості приймача визначаються значення енергетичних перевищень сигналу і сумарних перешкод над шумами в точках прийому по лініях зв'язку.

- Розрахунок значень коефіцієнта структурної взаємодії сигналу i сукупності перешкод. 
«Системні технології» 1 (132) 2021 «System technologies»

- Розрахунок ймовірності бітової помилки з урахуванням статистичних характеристик ліній зв'язку між вузлами.

- Формування моделі топології мережі, зокрема встановлення зв'язків між вузлами, для яких виконується визначені критерії.

Для моделювання топології БСМ, в якості інструменту моделювання було використано Riverbed (OPNET) Modeler Academic Edition 17.5. Ця версія програми не тільки дозволяє розвивати надійну мережеву комунікацію та різні системні моделі, але також підтримує зв'язок між адміністратором, координатором PAN, маршрутизаторами та кінцевими пристроями. Під час моделювання маршрутизація сіток для топологій дерев та зірок була зроблена пасивною, але активною для топології сітки (рис.2). Час моделювання було встановлено на одну годину. Розмір пакетів даних, які слід надіслати, був визначений як 1024 байти, і ціль була обрана випадковим чином. Моделювання було проведено в Riverbed Modeler для вузлів датчиків для первинного збору інформації із свого оточення. Таким чином, датчики спілкувались один 3 одним, надсилаючи повідомлення один одному, і були отримані дані, необхідні для моделювання. Потім були відібрані загальні та об'єктні статистичні значення для подальшого використання при моделюванні, результати були записані та представлені у графічному форматі для інтерпретації.

На рис. 3. подано частину результатів проведеного моделювання, зокрема порівняльний аналіз топологій за пропускною здатністю та $з$ урахуванням «ефекту стіни».

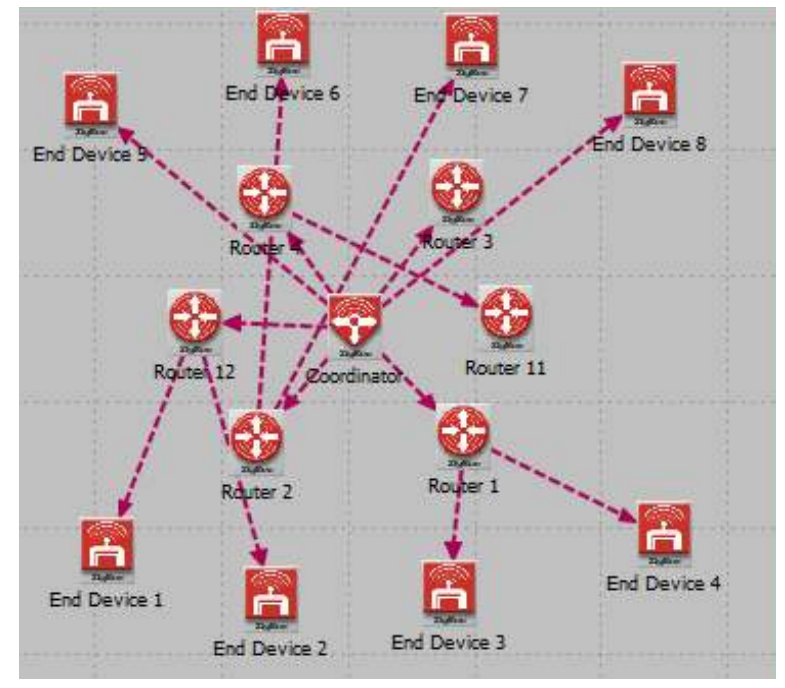

а) «дерево»

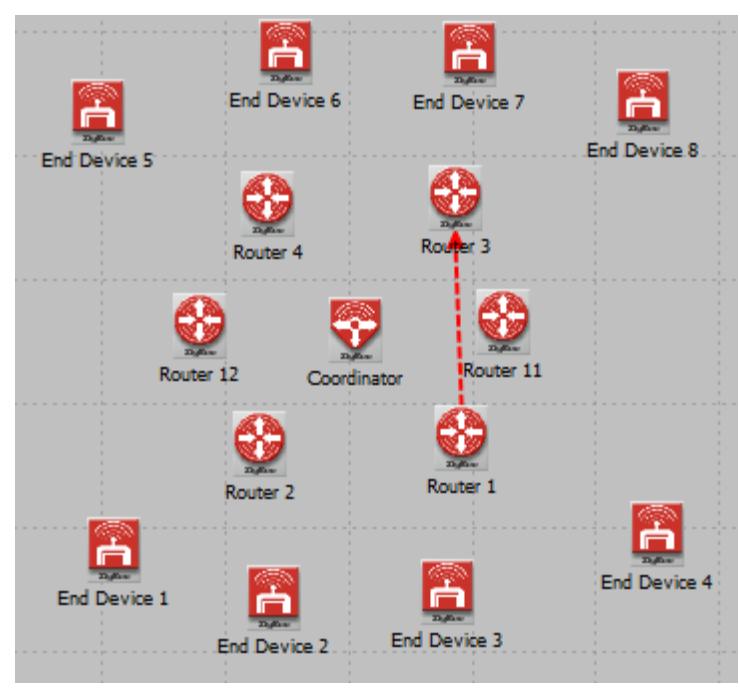

б) «сітка»

Рисунок 2 - OPNET-моделі різних топологій 
«Системні технологіï» 1 (132) 2021 «System technologies»

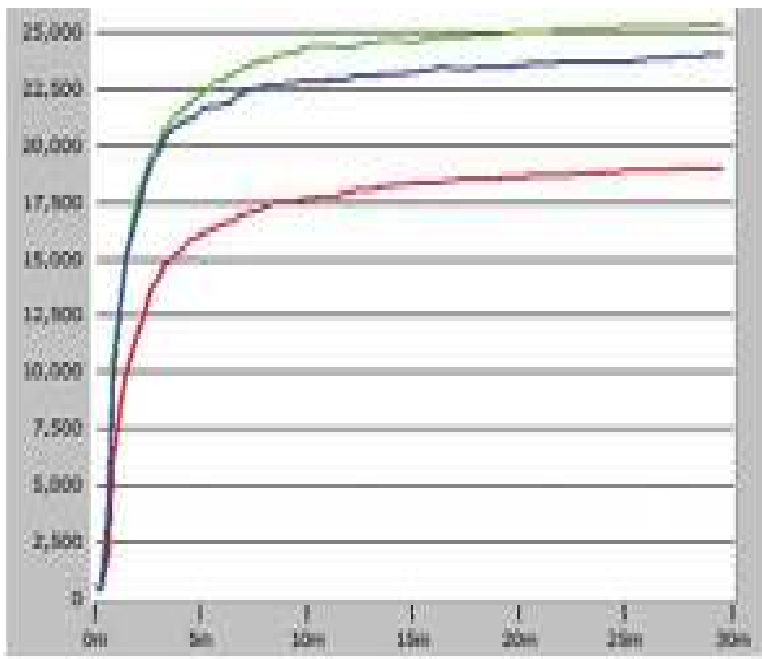

a)

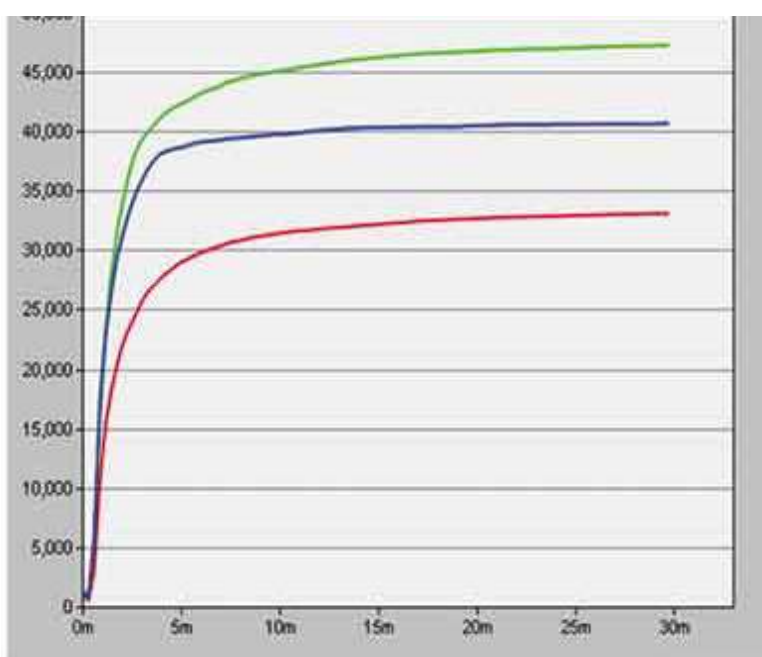

б)

Рисунок 3 - Порівняльний аналіз топологій (синій - сітка, червоний - зірка, зелений - деревоподібна): а) за пропускною здатністю; б) з урахуванням ефекту стіни

Висновки. Для вивчення топологічних особливостей БСМ в роботі здійснено порівняння трьох можливих топологій (зірка, сітка та дерево) між собою та розглянуто статистику кінцевої затримки, пропускної здатності, завантаження. Результати вказують на те, що деревоподібна мережа має більшу пропускну здатність і кінцеву затримку, і збільшення кількості користувачів бездротового носія збільшує можливість падіння пакетів у мережах зірок. Результати моделювання показують, що згасання погіршує продуктивність мережі та накладні витрати на маршрутизацію. Зроблено висновок, що продуктивність на основі зірок прийнятна для малих мереж, тоді як на основі сітки найкраще підходить для мереж з великою кількістю мобільних вузлів.

\section{ЛIТЕРАТУРА / ЛИТЕРАТУРА}

1. Sobin C. A Survey on Architecture, Protocols and Challenges in IoT. Wirel Pers Commun. 2020; 112: 1383-1429. https://doi.org/10.1007/s11277-020-07108-5.

2. Alahmadi H., Bouabdallah F. Multichannel preamble sampling MAC protocol for wireless sensor networks. Int. J. Distrib. Sens. Networks. 2019; 15: 155014771985095. https://doi.org/10.1177/ 1550147719850951.

3. Masud F., Abdullah A., Altameem A., Abdul-Salaam G., Muchtar F. Traffic Class Prioritization-Based Slotted-CSMA/CA for IEEE 802.15.4 MAC in Intra-WBANs. Sensors. 2019; 19: 466. https://doi.org/10. 3390/s19030466. 
«Системні технології» 1 (132) 2021 «System technologies»

4. Акимов Е.В., Кузнецов М.Н. Вероятностные математические модели для оценки надежности беспроводных сенсорных сетей // Труды МАИ. - 2010. Вып. № 40. - 13 с.

5. Недев М.Д. Синхронизация времени в сенсорных сетях // Программные системы: теория и приложения. - 2011. - С. 71-83.

6. Chen B.D., Varshney P.K. (2004). QoS support in wireless sensor networks: A survey. Proc. of Intl. Conf. on Wireless Networks (ICWN ‘04), Las Vegas, Nevada, USA.

7. Sun G., Zhao L., Chen Z., Qiao G. Effective link interference model in topology control of wireless Ad hoc and sensor networks. Journal of Network and Computer Applications, 2015, vol. 52, pp. 69-78.

\section{REFERENCES}

1. Sobin C. A Survey on Architecture, Protocols and Challenges in IoT. Wirel Pers Commun. 2020; 112: 1383-1429. https://doi.org/10.1007/s11277-020-07108-5.

2. Alahmadi H., Bouabdallah F. Multichannel preamble sampling MAC protocol for wireless sensor networks. Int. J. Distrib. Sens. Networks. 2019; 15: 155014771985095. https://doi.org/10.1177/ 1550147719850951.

3. Masud F., Abdullah A., Altameem A., Abdul-Salaam G., Muchtar F. Traffic Class Prioritization-Based Slotted-CSMA/CA for IEEE 802.15.4 MAC in Intra-WBANs. Sensors. 2019; 19: 466. https://doi.org/10. 3390/s19030466.

4. Akimov E.V. Sravnenie topologiy besprovodnykh sensornykh setey [Comparison of topologies of wireless sensor networks], Vestnik komp'yuternykh i informatsionnykh tekhnologiy [Herald of Computer and Information Technologies], 2008, No. 8, pp. 240.

5. Nedev M.D. Sinkhronizatsiya vremeni v sensornykh setyakh [Time synchronization in sensor networks], Programmnye sistemy: teoriya i prilozheniya [Program Systems: Theory and Applications], 2011, pp. 71-83.

6. Chen B. D., Varshney, P. K. (2004). QoS support in wireless sensor networks: A survey. Proc. of Intl. Conf. on Wireless Networks (ICWN '04), Las Vegas, Nevada, USA.

7. Sun G., Zhao L., Chen Z., Qiao G. Effective link interference model in topology control of wireless Ad hoc and sensor networks. Journal of Network and Computer Applications, 2015, vol. 52, pp. 69-78.

Received 15.01.2021. Accepted 19.01.2021.

\section{Моделирование топологии беспроводных сенсорных сетей}

Основной проблемой исследований беспроводных сенсорных сетей (БСМ) является моделирование топологией сети. В работе проведено сравнение возможных топологий 


\section{«Системні технології» 1 (132) 2021 «System technologies»}

беспроводных сенсорных сетей между собой и рассмотрены статистики конечной задержки, пропускной способности, загрузки. Результаты указывают на то, что древовидная сеть имеет большую пропускную способность и конечную задержку. Кроме того, угасание ухудшает производительность сети в конце задержки и накладные расходы на маршрутизацию. Сделан вывод, что производительность сети с топологией звезды приемлема для малых сетей, тогда как на основе сетки лучше всего подходит для сетей с большим количеством фиксированных и мобильных узлов.

\section{Simulation of wireless sensor network topologies}

Among the main problems of research of wireless sensor networks are modeling and management of network topology in order to increase its connectivity, as well as routing with minimal time and energy costs. The wireless sensor networks topology is usually understood as a model that describes the structure of connections between elements within a network. However, the solution of these problems is impossible without taking into account the states of communication between nodes. The lack of an effective approach to estimating the different interaction of nodes leads to the fact that theoretical calculations on simplified models of wireless sensor networks topology do not coincide with the results of experimental studies of networks. The paper compares the possible topologies of wireless sensor networks with each other. The network topology modeling algorithm consists of the following main stages: calculation of distances between nodes; the radius determining the radio capture zone of the transmitter as a possible source of interference; signal power calculation; values calculation of the structural interaction signal coefficient and the set of interferences; calculation of the probability of bit error taking into account the statistical characteristics of the communication lines between nodes; formation of a network topology model, in particular the establishment of connections between nodes for which certain criteria are met. The results indicate that the tree network has higher throughput. In addition, fading degrades network performance and routing overhead. It is concluded that the performance of a network with a star topology is acceptable for small networks, while a mesh network is best suited for networks with a large number of mobile nodes. The practical significance of the results obtained lies in the possibility of using the proposed approach to optimizing the topology of wireless sensor networks, as well as the developed software product when solving problems related to the design of the topology of wireless sensor networks.

Ковальова Юлія Вікторівна - асистент кафедри безпеки інформації та телекомунікацій Національного технічного університету «Дніпровська політехніка» (м. Дніпро).

Ковальова Юлия Викторовна - ассистент кафедры безопасности информации и телекоммуникаций Национального технического университета «Днепровская политехника» (г. Днепр).

Kovalova Yuliia - assistant of the Department of Information Security and Telecommunications, Dnipro University of Technology, Ukraine. 